\title{
The Relationship between Economic Growth, Small and Medium Enterprises and the Number of Employees in Malaysia using Vine Copula Approach
}

(Hubungan antara Pertumbuhan Ekonomi, Perusahaan Kecil dan Sederhana dan Jumlah Pekerja di Malaysia menggunakan Pendekatan Vain Kopula)

\author{
MAZMIRA ADAN \& SAIFUL IZZUAN HUSSAIN*
}

\begin{abstract}
This paper investigates the dynamic linkages of dependency between economic growth, the development of small and medium enterprises (SMEs) in Malaysia represented by SMEs'value-added, and the number of employees in Malaysia, shown by the total number of SMEs' employees in Malaysia as an additional variable. A vine copula methods was used to assess the linkage between these three variables by utilizing the panel data sets from 1998-2017. The results confirmed that dependency modeling, using vine copulas, is useful for high dimensional distributions of binding affinity between these variables. Vine copulas provide a versatile and flexible approach to the study. The results show that there is a strong positive correlation among the variables. The dependence between the SMEs'growth and the total number of employees is the strongest, followed by the dependence between SMEs' growth and economic growth. This study also found that the interrelation among the variables and reliance structure is also influenced by the country's economic system and situation.
\end{abstract}

Keywords: Copula; economic growth; SMEs; vine copula

ABSTRAK

Penyelidikan ini mengkaji tentang hubungan kebergantungan dinamik antara pertumbuhan ekonomi, pertumbuhan perusahaan kecil dan sederhana (PKS) Malaysia dan juga jumlah pekerja di Malaysia yang diwakili oleh jumlah pekerja PKS di Malaysia sebagai pemboleh ubah tambahan. Pendekatan vain kopula digunakan untuk menilai hubungan antara tiga pemboleh ubah ini dengan menggunakan set data panel yang meliputi tempoh 1998-2017. Hasil kajian menunjukkan bahawa penggunaan vain kopula membolehkan hubungan yang penting di kalangan pemboleh ubah membentuk model kebergantungan untuk taburan berdimensi tinggi. Pendekatan ini menawarkan kefleksibelan yang tinggi dan sangat sesuai digunakan untuk kajian ini. Hasilnya menunjukkan bahawa terdapat korelasi positifyang kukuh antara pemboleh ubah dan kebersandaran antara pertumbuhan PKS dan jumlah pekerja adalah yang paling tinggi, diikuti oleh kebersandaran antara pertumbuhan PKS dan pertumbuhan ekonomi. Kajian ini juga mendapati bahawa hubungan dinamik antara pemboleh ubah yang dikaji turut dipengaruhi oleh struktur dan keadaan ekonomi negara.

Kata kunci: Kopula; pertumbuhan ekonomi; PKS; vain kopula

\section{INTRODUCTION}

SMEs are one of the most crucial elements in current economic development and growth. They contribute by reducing the poverty level and help people increase their income by generating job opportunities in the broader SME sector. SMEs also expand economic activities and provide a comprehensive source of resources to assist growth, among others. Apart from providing support 
services and being a supplier to large firms, SMEs also stimulate entrepreneurship skills in the population and boost developing domestic companies into large companies (Habaradas 2008). As stated by Leonelli et al. (2019), entrepreneurial orientation is especially important for economic growth, innovation, and employment.

Apart from assisting in economic development, they also help create job opportunities. Worldwide, SMEs are seen as dynamic contributors to a country's economic development. Craig et al. (2008) report that the SMEs sector in the U.S. acts as an incubator for employment and also helps innovation. Accordingly, Altman and Sabato (2007) stated that $97 \%$ of the total number of firms registered in the Organization for Economic Co-operation and Development (OECD) countries are SMEs. SMEs support the formulation of usage efficiency policies, which amplify entrepreneurial activities and produce improved employment opportunities (Adeoye \& Abu 2015). They provide nearly $75 \%$ of a country's jobs.

Vermeulen (2011) agreed that SMEs contribute significantly to the economy by being an economic growth engine, increasing business market competitiveness and efficiency. SMEs also play a critical role in developing countries, for example, helping to reduce poverty rates. Similarly, Audretsch and Keilbach (2004) agreed that SMEs are important determinants of economic growth. Some researchers suggest that SMEs are needed to enhance social progress and increase job opportunities, as prosperous countries have small enterprise sectors that function well in their economic environment (Nager et al. 2014).

According to Ayandibu and Houghton (2017), though SMEs contribute immensely toward a country's economic development, they still face significant challenges. One such challenge is the difficulty in accessing finance (Wang 2016). SMEs also face the challenges such as low of marketing capabilities and lack of $R \& D$ expenditures which are some of the reasons behind the slow growth of SMEs. Special treatment should be given to them to enhance their performance and affect the economy positively. The government should create suitable methods for easing SMEs financing such as by developing credit guarantee schemes or trust funds investment. The contribution to business R\&D through tax incentives could boost SMEs growth (Yoshino \& Taghizadeh-Hesary 2016). Bello et al. (2018) proposed that the government should present a policy that could protect local producers against the importation of foreign goods, especially for those products that can be produced locally. Although rivalry is healthy for business, SMEs, as a small business, need the market space for their products in the country. Chinweuba and Sunday (2015) showed that the expansion of output and other business activities helps SMEs to survive and enhance growth. Individual efforts need to be taken to ensure that sufficient facilities are available. All the above reasons make SMEs interesting to be study.

\section{SMES IN MALAYSIA}

SMEs are the highest contributor or primary economic driver in Malaysia, accounting for about $98.5 \%$ of the total commercial establishments. They contributed 38.3\% of the country's GDP. An increase of $6.2 \%$ in the GDP was registered in 2018, slightly higher than the longterm average increase of $6.0 \%$ for 2001-2017. This increase was due to the growth of essential activities in SME sectors such as services and manufacturing and the growth of SME exports (Department of Statistics Malaysia 2019). A New Economic Model (NEM) presented by the government in 2015 that mainly focused on domestic SMEs was based on the significance of SMEs to the nation. The NEM has highlighted SMEs' essential growth factor for Malaysia to become a high-income country by 2020 (TalentCorp Malaysia 2015). As expected, the growth of Malaysia's SMEs has shown improvement. It can be viewed in Figure 1, where the plotted graph shows the increase over the years. This growth proves that the SMEs performed well, and are growing, slightly above the long-term average growth.

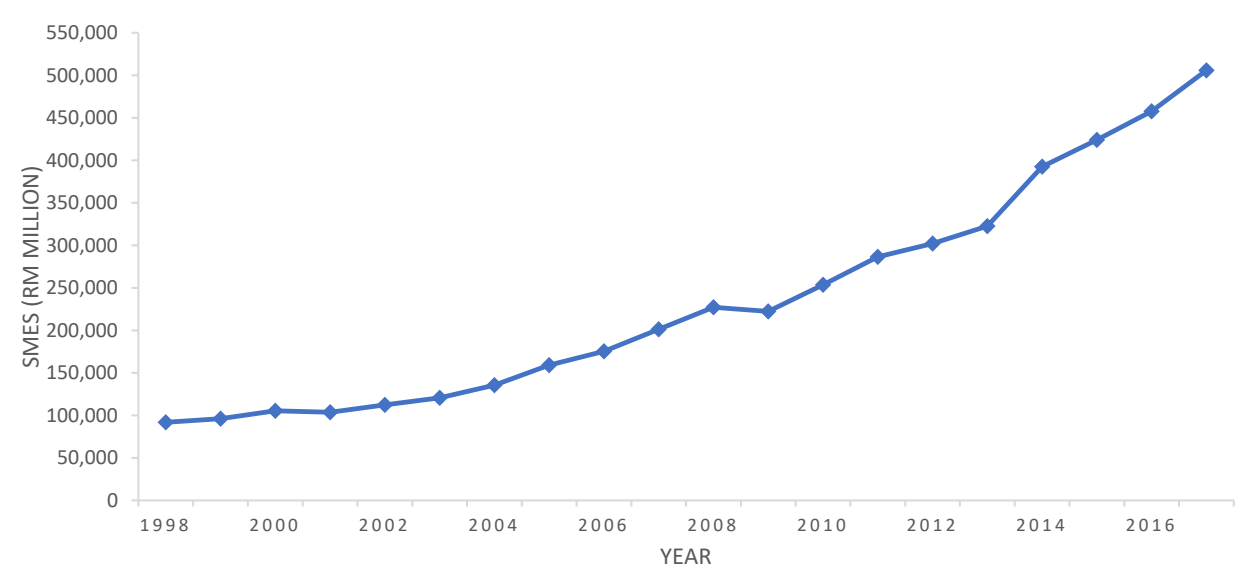

FIGURE 1. Malaysia SMEs' value-added 
GDP

Economic development is often related to an increase in the country's GDP, which has been used as a measurement tool to determine the country's economic direction. GDP is the indicator of a nation's total economic activity that substitutes the monetary worth for all goods and services generated during a particular time. It calculates goods and services for each total earning and total expenditure of the economy. Consequently, governments can know their current economic situation. The higher the GDP, the better the economy is performing. In developed Asian countries such as Japan, SMEs' contribution to GDP exceeds 55\% compared to Malaysia, which only contributed 38.3\% in 2018 (Malaysia SME Corp. 2019).

Economic development is thought to be associated with many elements of SMEs' growth: They complement each other and have related processes. Accordingly, there is a positive linkage between SME success and the growth of the economy. Successful SMEs will positively influence economic growth (Scheers 2016). However, it is not evident how SMEs directly affect economic growth. The relationship tends to be indirect rather than direct (Ayandibu \& Houghton 2017). There are other opinions, such as Tambunan (2008), who reported that SME growth is affected by both actual GDP and government development expenditure. As in the case of Malaysia, which is shown in Figure 2, the growth trend of Malaysia's GDP was approximately in line with the yearly SME growth (see Figure 1 for SME growth). Thus, it can be concluded that the Malaysian GDP has a relationship with the economy, which mostly comprises SMEs.

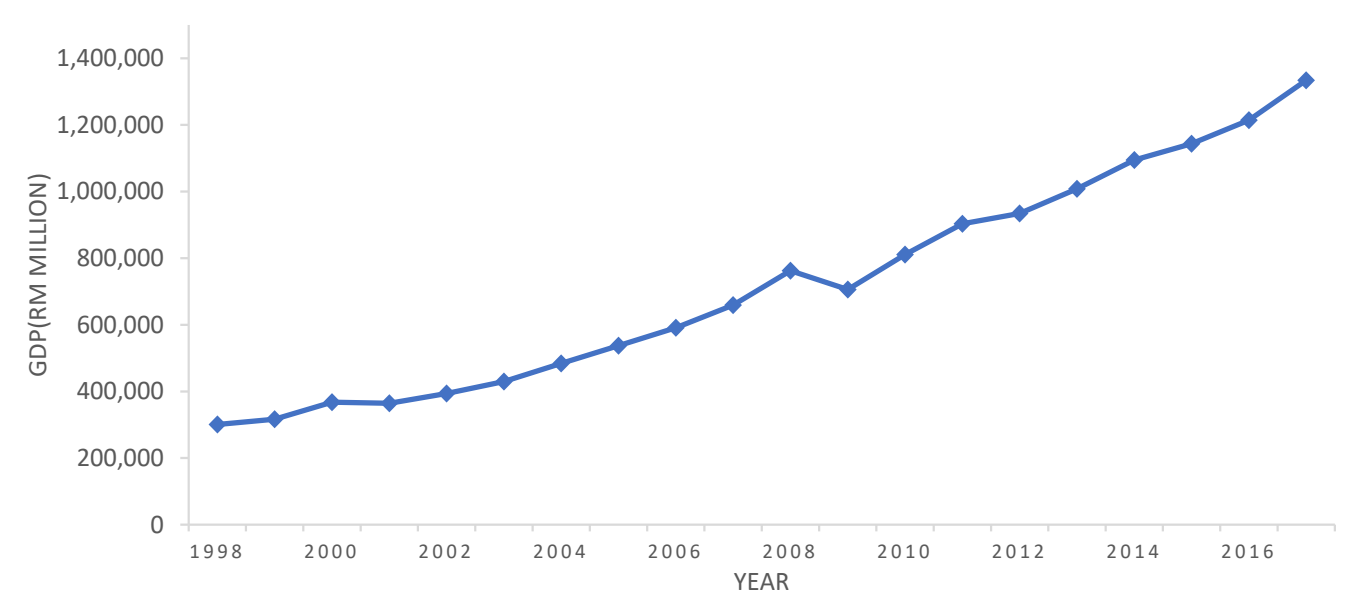

FIGURE 2. Malaysia GDP

\section{EMPLOYEE}

Employees are the leading players in business development and drive economic growth. The number of employees in each economic activity depends on the performance of that activity in response to economic conditions. In Malaysia, the growth of SMEs drives strong growth in employment, which also contributes to sustainable economic development. It is the sector that provides the greatest job opportunities as it is one of the fastest-growing sectors in the world. Compared to other sectors, SMEs offer investment opportunities with quick returns, which are attractive to investors (Malaysia SME Corp. 2014). 
Figure 3 shows the number of employees in SMEs from 1998-2017, rising annually. This rise reflects the nation's economic growth and simultaneously proves that the increasing number of workers is dependent on economic growth.

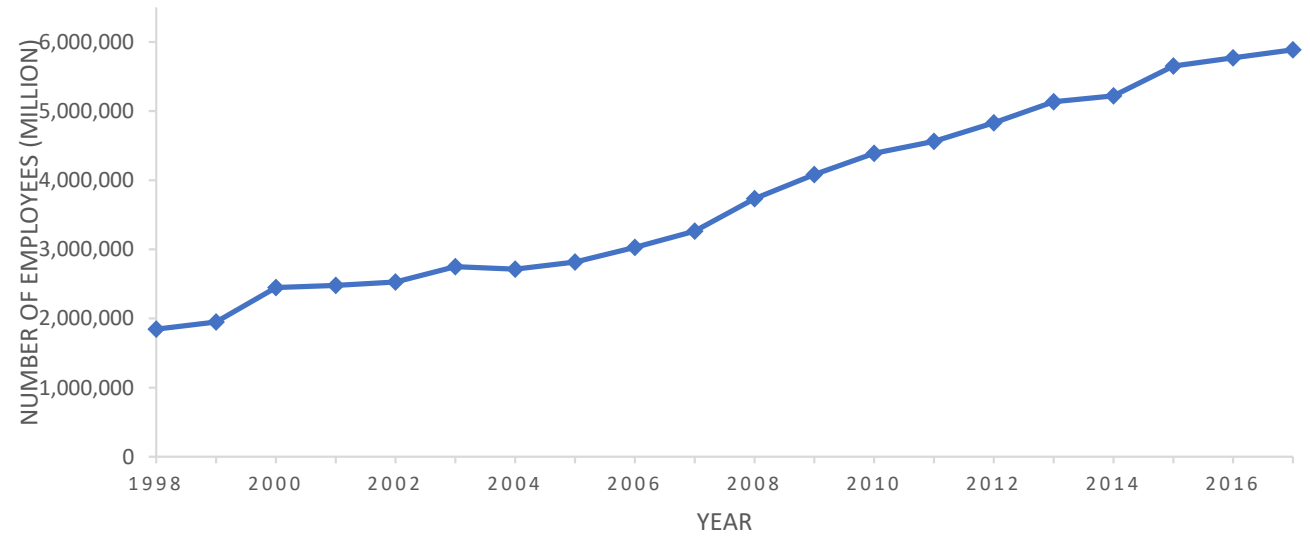

FIGURE 3. Number of SMEs' Employees in Malaysia

\section{LITERATURE REVIEW}

Most of the literature research refers to the impact of SMEs on the expanding economy as the direct causation. The influence of SMEs on the economic growth was described by many authors like Muritala et al. (2012) and Opafunso and Adepoju (2014) proved that SMEs are a very important tool used by developed countries to gain economic growth. Audretsch and Keilbach (2004) and Beck et al. (2005) assessed the impact of entrepreneurship in developed countries on economic growth. While Scheers (2016) investigated the determinants of the role of SMEs and found that there was a positive relationship and simultaneously that SMEs are a stimulus for economic growth.

Karadag (2016) found that the economic growth and development of the SME sector are combined in both developed and developing countries. However, elements such as the creation of innovation, occupation, and the contribution of the SME sector value-added to the economy differ widely throughout distinct contexts. Therefore, it is no wonder that various research continues to expand techniques and strategies for improving SME overall performance (Lussier et al. 2016).

As suggested by Wozniaka et al. (2019), SMEs contributed to the creation of GDP and also play a role in reduction of unemployment. Findings by Ayozie and Latinwo (2010) and Muritala et al. (2012) showed that the effect of SMEs on the country's development as they create employment and contribute to the gross domestic product (GDP). Similar research was conducted by Prusa (2010) showing that SMEs were closely linked to GDP which is the indicator to economic growth and also employment factor. Irrespective of the level of economic growth worldwide, most countries continue to implement policies and programs that can create and pave the way for their sustainable economic development through the development of SMEs (Bello et al. 2018). This implementation proves that SMEs are increasingly 
significant in the development of a country's economy. All the papers showed SMEs may have robust positive consequences on the growth of the economy, which is considered as direct causation in this study.

Although SMEs were seen as drivers for economic growth, in certain country despite strong support for SMEs, the economic growth is still low (Wozniaka et al. 2019). In the similar vein, Roopchund (2020) found that there is no linkage between SMEs growth and unemployment rate and economic growth in Mauritius. Meanwhile, Hu (2010) showed that SMEs have no effect on economic growth unless the SME sector is capable to generate huge number of employments. Leegwater and Shaw (2008) showed that the finding of their study do not support SMEs' prevalence that SMEs positively affects economic growth. This indicates that though many researchers examining the area, there are still gaps to be filled.

Recently, research on vine copula has increasingly become more critical and favoured by academics. This flexibility of modeling multivariate distributions has been utilized in many learning tasks and has emerged as a common tool in financial economics. This study expands the analysis of copula to vine copula for greater empirical evaluation of the connection between economic growth, SMEs, and the number of employees for 19982017. Standard multivariate copulas can end up rigid in modeling, resulting in high dimensional dependence. Different dependency structures also do not permit the dependency between pairs of variables. However, the vine is different, as it is verified as a flexible tool in high dimensions.

Vine copulas as pliable models of complex dependence patterns can be organized in a tree structure, using the rich diversity of bivariate copulas to facilitate the analysis of multiple dependencies. This approach is known as distributions with the flexible option of applying model co-dependencies. Using the vine copula brings significant benefits as bivariate copulas can freely choose from copula families (Aloui \& Ben Aissa 2016). As a pliable graphical model, the vine explains pair-copulas, which is a cascade of bivariate copulas constructed for multivariate copulas. Liao et al. (2019) use a C-vine copula in their study on the dependence structure between the stock market and oil return in developed and developing countries. Sun (2019) applied vine copula to analyze the price linkage between oil, gold, stock, and exchange rates. Other studies indicated that vine copulas not only capture the multivariate dependence at a dissimilar duration of vibrations but can also capture their tail dependence, which is essential to the estimation of losses at low probability high-impact risk (Cheng et al. 2020).

Although this approach has been used very effectively in many studies, such usage is still rare. Therefore, this study intends to empirically analyze the linkage between SMEs, GDP, and employees based on the vine copula measure correlations. The gap between this study and prior researches is considered and used as guidance to determine the dependency between SMEs, GDP growth, and SME employees. Applying the vine copula method is the most feasible and efficient approach when considering dependency. This study is integral to the researchers' aim of examining and perceiving the correlation between the development of SMEs and the expansion of Malaysia's economy.

Overall, it is crucial to determine the dependency between them. We have not found a study in the literature on SME growth that uses the vine copula as an approach to investigate the dependency between SMEs and economic growth. Most of the studies undertake different methods and show conflicting evidence. This study was conducted to describe and show the statistical dependency between SMEs and economic growth as measured by the GDP using copula. This study also aims to show that SMEs are either the main driver contributing to the country's growth, or vice versa, or even that they are co-dependent. Policymakers need to be aware of the level of dependency between the variables so they will be able to make effective economic policies.

\section{DATA AND METHODS}

This section discusses the data and the methods applied in the study.

\section{DATA}

This analysis considers the aggregated data that comprise from five major economic activities in Malaysia. This study used Malaysia's GDP data and data of the valueadded by Malaysia's SMEs' to economic activities in Ringgit Malaysia. Data on the total number of SMEs' employees is used as an additional variable. The GDP is used to represent Malaysia's economic growth. Barro (2002) mentions that the ideal substituted for economic growth is the GDP's growth. Thus, this study applies GDP data to represent the growth of the country's economy. 
The annual data used in this study comes from five major economic activities, namely agriculture, mining, construction, manufacturing, and services, which are shown in Figure 4. The data covers 1998-2017, which are based on census and survey conducted by the Department of Statistics Malaysia.
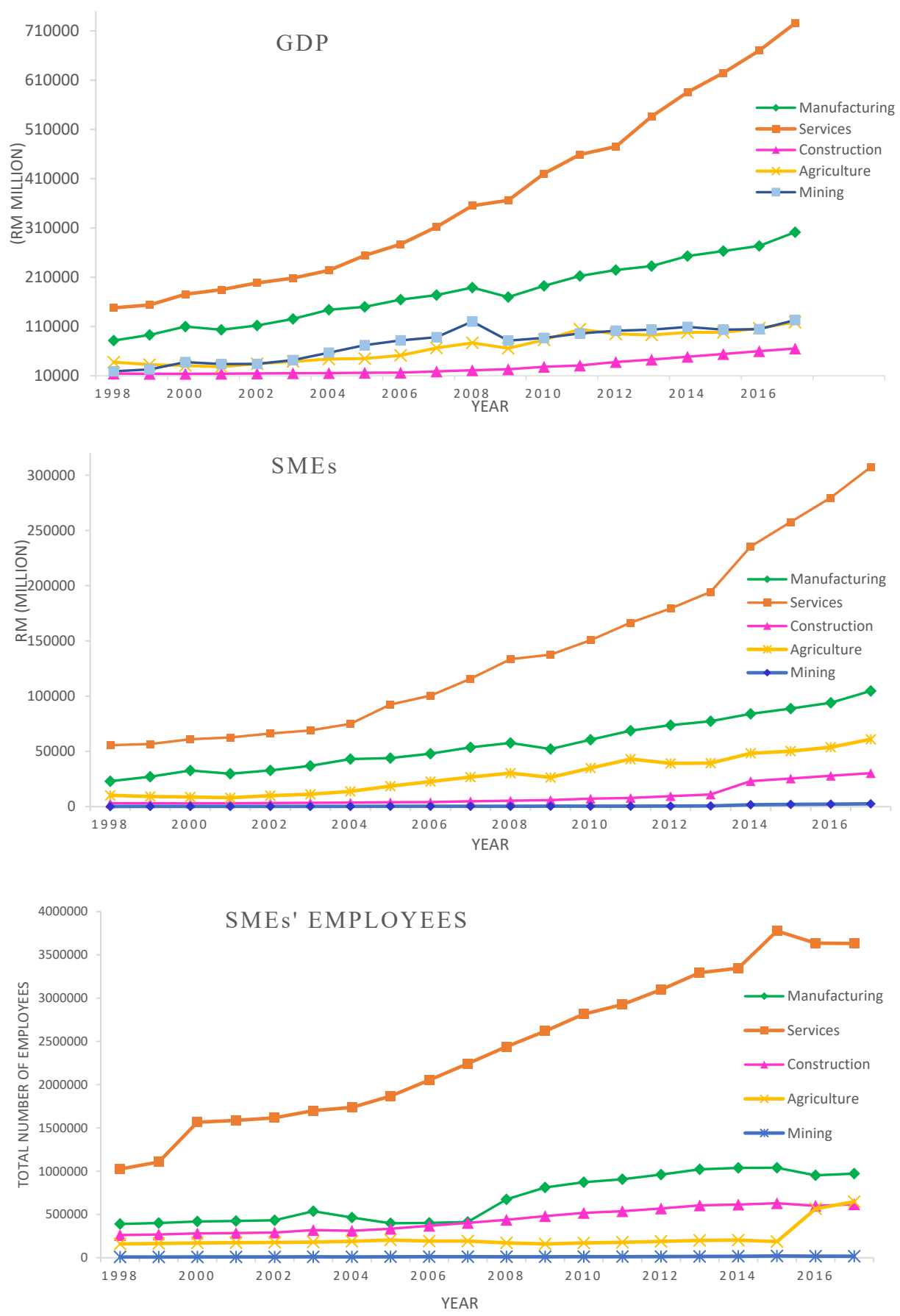

FIGURE 4. GDP, SMEs, and SMEs employees by activities 
TABLE 1. Descriptive statistics

\begin{tabular}{lccccc}
\hline & Mean & $\begin{array}{r}\text { Standard } \\
\text { deviation }\end{array}$ & Skewness & Kurtosis & Jarque-Bera \\
\hline SMEs & 0.035 & 0.895 & -4.688 & 38.678 & 5758.702 \\
GDP & 0.030 & 0.492 & -2.359 & 21.630 & 3259.381 \\
Employees & 0.032 & 0.653 & -1.547 & 43.124 & 1432.210 \\
\hline
\end{tabular}

Table 1 presents the descriptive statistics of the differenced data. It shows that the mean (average) of the data is positive for all variables. The GDP have the lowest standard deviation, which suggests that the GDP data tend to be close to the mean of the data set, whereas SMEs has the highest. The SMEs' data are spread over a broader range. According to the skewness principle, a normal distribution has a skewness of zero. All the skewness values are negative, and the category for employees has the value which is nearest to the normal distribution. Meanwhile, all the variables showed a positive kurtosis which indicates a leptokurtic distribution. This distribution shows the heavier tails on either side, between those variables which show the large outliers. The series depicts a higher than a normal distribution. The Jarque-Bera test is a goodness-of-fit test, and it tests if the data have a normal distribution. Jarque-Bera test result is far from zero, it confirms that the data do not have a normal distribution.

\section{Methods}

This study uses the data which are not in the normal distribution, which is not problematic, as it uses the vine copula approach to model the dependencies between the variables. For extra detail on the information of the relationships' solidity, the vine copula method is used to describe how strong the connection is and also to describe the dependency information. This method is very flexible in the choice of distribution. This section explains the construction of the vine copula and methods that has been employed.

\section{VINES COPULAS}

Joe (1996) proposed vine copulas and they were explicitly developed by Bedford and Cooke $(2002,2001)$ and Kurowicka and Cooke (2006). A probability density of a multivariate can be decomposed into bivariate copulas with the construction of a pair-copula and can be chosen independently. In particular, the asymmetry and tail dependence can be considered as can the (conditional) independence to construct more detailed models.

Vine copulas allow the continuation of greater dimensions and are known as a flexible graphical model that uses pair-copulas. The modeling scheme may be chosen independently to allow for a broad variety range of dependence; the basis is on an unraveling probability density of a multivariate into bivariate copula densities, which is $d(d-1) / 2$. Two fundamental types of paircopulas are $\mathrm{C}$ - and D-vine copula models. Let us consider three random variables $X=\left(x_{1}, x_{2}, x_{3}\right)$ with distribution functions of marginal, $F_{1}, F_{2}$ and $F_{3}$ and joint densities of the pair-copula development for three dimensions. A plausible substitute for the joint density is presented as (1):

$$
f\left(x_{1}, x_{2}, x_{3}\right)=f_{1}\left(x_{1}\right) f\left(x_{2} \mid x_{1}\right) f\left(x_{3} \mid x_{1}, x_{2}\right)
$$

Sklar theorem states that a copula density and univariate marginal densities can be disassembled from the joint density. This theorem is for the conditional density of $x_{2}$ given $x_{1}$ that as (2):

$$
\begin{aligned}
f\left(x_{2} \mid x_{1}\right) & =\frac{f\left(x_{1}, x_{2}\right)}{f_{1}\left(x_{1}\right)}=\frac{C_{1,2}\left(F_{1}\left(x_{1}\right), F_{2}\left(x_{2}\right)\right) f_{1}\left(x_{1}\right), f_{2}\left(x_{2}\right)}{f_{1}\left(x_{1}\right)} \\
& =c_{1,2}\left(F_{1}\left(x_{1}\right), F_{2}\left(x_{2}\right)\right) f_{2}\left(x_{2}\right)
\end{aligned}
$$


While for three random variables $X_{1}, X_{2}$ and $X_{3}$, as (3):

$$
\begin{gathered}
f\left(x_{3} \mid x_{1, \mathrm{X}}\right) \frac{f\left(x_{2}, x_{3} \mid x_{1}\right)}{f\left(x_{2} \mid x_{1}\right)}=\frac{C_{2,3 \mid 1}\left(F\left(x_{2} \mid x_{1}\right), F\left(x_{3} \mid x_{1}\right)\right) f\left(x_{2} \mid x_{1}\right) f\left(x_{3} \mid x_{1}\right)}{f\left(x_{2} \mid x_{1}\right)} \\
=c_{2,3 \mid 1}\left(F\left(x_{2} \mid x_{1}\right) F\left(x_{3} \mid x_{1}\right) c_{1,3}\left(F_{1}\left(x_{1}\right), F_{3}\left(x_{3}\right)\right) f_{3}\left(x_{3}\right)\right.
\end{gathered}
$$

Therefore, the density of the three-dimensional joint (1) is illustrated using the densities of bivariate conditional copulas and marginal as (4):

$$
\begin{gathered}
f\left(x_{1}, x_{2}, x_{3}\right)=c_{2,3 \mid 1}\left(F\left(x_{2} \mid x_{1}\right), F\left(x_{3} \mid x_{1}\right) c_{1,2}\left(F_{1}\left(x_{1}\right), F_{2}\left(x_{2}\right) c_{1,3}\left(F_{1}\left(x_{1}\right) F_{3}\left(x_{3}\right)\right)\right.\right. \\
f_{1}\left(x_{1}\right), f_{2}\left(x_{2}\right) f_{3}\left(x_{3}\right)
\end{gathered}
$$

A graphical model referred to as a common vine was initiated by Bedford and Cooke (2001). It assists in the arranging of the high dimensional distribution, where there is a vast quantity of chance pair-copula decompositions. This study focuses on two specific common vines, the $\mathrm{C}$ - and $\mathrm{D}$-vine. In a canonical vine structure, one unique node of the tree is connected to all nodes of the tree. Each pair of bivariate copulas is used to model the dependence in the first $\mathrm{C}$-vine tree for the first root node. The second root node is modeled conditioned on this variable, using pairwise dependencies for the second variable. The idea is that all other variables are linked to the variable that performs an essential function in the dependency structure. However, D-vines are specially identified via their route structure of the first tree. So, the complete D-vine tree sequence is defined by the order variables in the first tree.

After determining the vine structure that is to be applied and each pair of copula families, and the variables' conditional pair, the parameters are evaluated by sequence via the maximum likelihood beginning from the first tree (Czado et al. 2009). The C-vine copula log-likelihood function is shown by (5):

$$
\begin{gathered}
l_{\mathrm{cv}}\left(\theta_{\mathrm{cv}} \mid u\right)=\sum_{k=1}^{N} \sum_{i=1}^{d-1} \sum_{j=1}^{d-i} \\
\log \left[c _ { i , i + j | 1 : ( i - 1 ) } \left(F_{i \mid 1:(i-1),} F_{i+j \mid 1:(i-1)} \mid \theta_{i, i+j \mid 1:(i-1))]}\right.\right.
\end{gathered}
$$

where the parameter set of the $\mathrm{C}$-vine copula indicates by $\theta_{\mathrm{CV}}$ with the consistent of $F\left(U_{k j} \backslash U_{k, i_{1}}, \ldots, U_{k, i_{m}}\right)$ and the marginal distributions. So that, the D-vine copula loglikelihood function is as (6):

$$
l_{D V}\left(\theta_{\mathrm{DV}} \mid u\right)=\sum_{k=1}^{N} \sum_{i=1}^{d-1} \sum_{j=1}^{d-i}
$$

$\log \left[c_{j, j+i \mid(j+1):(j+i-1)}\left(F_{j \mid(j+1):(j+i-1)}, F_{j+i \mid(j+1):(j+i-1)} \mid \theta_{j, j+i \mid(j+1):(j+i-1)}\right)\right]$

The maximum likelihood estimation techniques are approximately employed on the parameters of the $\mathrm{C}$ - and D-vine copulas.

\section{RESULTS}

The analysis for this paper starts with the results from bivariate copula and extend to vine copula.

\section{BIVARIATE COPULA}

The vine copula is the copula analysis that extends from the bivariate copula. The study used Gaussian, Student-t, Clayton, Gumbel, and Frank copula, which derive from

\begin{tabular}{|c|c|c|c|c|c|c|}
\hline & & Gaussian & Student- $\mathrm{t}$ & Clayton & Gumbel & Frank \\
\hline SMEs & Parameter & 0.921 & $0.901,2.00$ & 4.496 & 3.862 & 11.353 \\
\hline vs & AIC & -179.307 & -180.126 & -171.433 & -184.146 & -145.437 \\
\hline EMP & BIC & -176.702 & -174.916 & -168.828 & -181.540 & -142.832 \\
\hline SMEs & Parameter & 0.779 & $0.789,6.251$ & 5.235 & 2.938 & 7.922 \\
\hline vs & AIC & -85.485 & -85.748 & -182.146 & -129.923 & -92.175 \\
\hline GDP & BIC & -82.880 & -80.538 & -179.541 & -127.318 & -89.570 \\
\hline GDP & Parameter & 0.677 & $0.673,30$ & 2.666 & 2.113 & 5.028 \\
\hline vs & AIC & -54.524 & -51.838 & -105.865 & -79.923 & -50.290 \\
\hline EMP & BIC & -51.919 & -46.628 & -103.260 & -77.318 & -47.685 \\
\hline
\end{tabular}
Archimedean and Elliptical families of copula to help translate how the variables in this study are related to each other by testing their goodness-of-fit test using the AIC and BIC. The lower of the AIC and BIC values will reflect the improved level of data fit to the model.

TABLE 2. Bivariate copula results

*Note: Data is for entire Malaysia (not divided by activity), GDP is Growth Domestic Product, SMEs is small medium enterprises and EMP is SMEs' employees. Student-t copula shows two parameters as this type of copula captured two-tailed dependence 
Table 2 shows the standard bivariate results of estimation from five types of copulas for the pairs of three variables of the Malaysian economy. The study selects the copula family that covers a wide range of dependence structures (Gaussian, Student-t, Clayton, Frank, and Gumbel). The Student-t copula has two parameters, whereas others have only one, as the Student-t copula captures two-tailed dependence. These values indicated dependence relationships. It was found that the SMEsEMP pair had established a strong positive dependence between them, and there are no negative correlations between all the pairs. This finding indicates that the total number of employees will increase if the growth of SMEs increases or vice versa.

\section{VINE COPULA}

Next, the vine copula is used for an in-depth investigation of the dependency between SMEs, GDP, and Employees. Vines can be a flexible tool in high dimensions when integrated with the bivariate copula. Figure 5 shows a pairs plot with a standard normal margins contour plot below and a scatter plot above the diagonal. A contour plot is a graphical description that may be applied for understanding the interrelation among the variables. It shows the two dimensions of the 3-dimensional relationship with $\mathrm{x}$ and $\mathrm{y}$ scales that are plotted with $\mathrm{x}$ and $y$ factors. The contour graph represents the response values. Clearly, there is a stronger dependency between the SMEs-Employee pair, based on diagonal density for all variable pairs. The GDP-Employee pair dependency also appears weaker than the others. The behavior of the tail's evidence for the SMEs-GDP pair shows that the data tend to focus on the lower diagonal, shown in the scatter plot. The tail behavior also occurred in the GDPEmployee pair, where the data focused on the upper and lower diagonals. The suitable techniques to explain on tail behavior for these pairs are the copula as it captures tail characteristics and dependence.

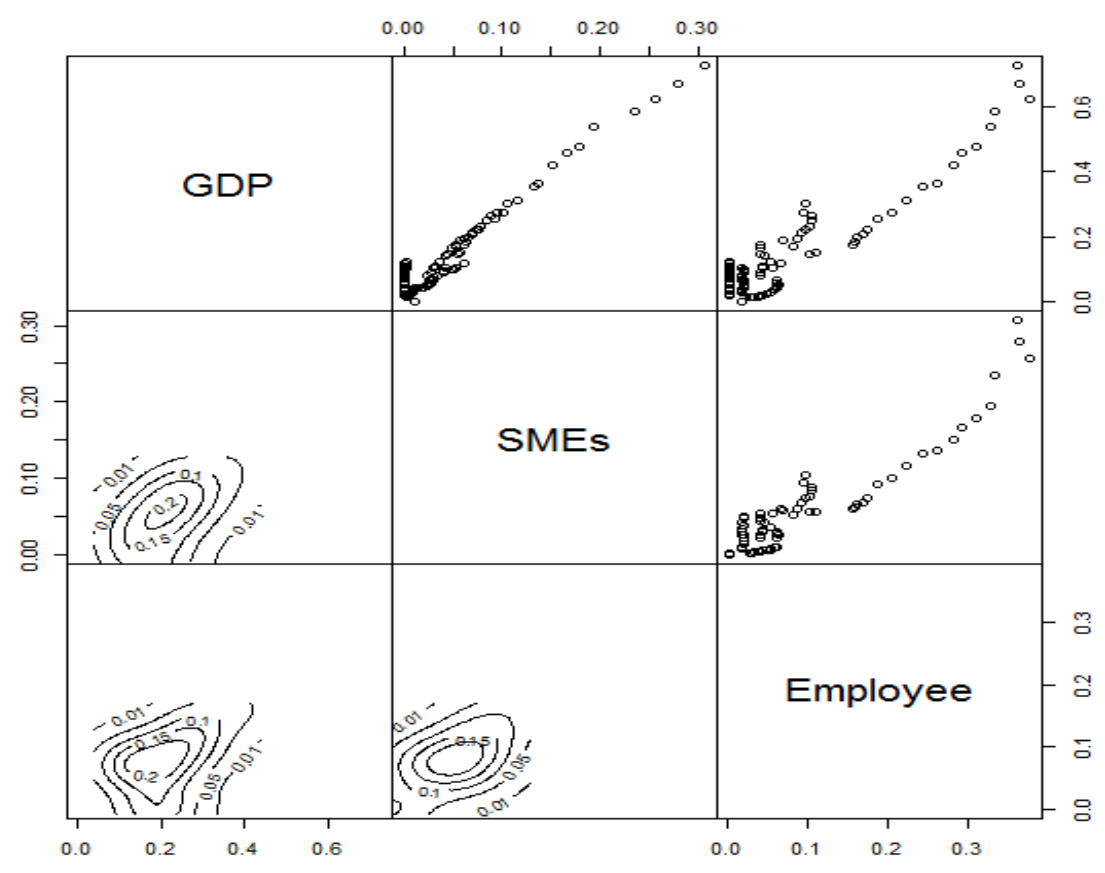

FIGURE 5. Copula with scatter and contour plots 
Table 3 presents the results of the estimated Kendall's tau, which showed that the dependence is positive for all pairs. The results are equal to $0.696,0.505$, and 0.748 for GDP-SMEs, GDP-EMP, and SMEs-EMP pairs, respectively. Those values are then applied to determine the sequence of the variable, where the variable with the most importance will be placed first in the sequence.

TABLE 3. Kendall tau correlation result

\begin{tabular}{llll}
\hline & GDP & SMEs & EMP \\
\hline GDP & 1.000 & 0.696 & 0.505 \\
SMEs & 0.696 & 1.000 & 0.748 \\
EMP & 0.505 & 0.748 & 1.000 \\
\hline
\end{tabular}

The first-level tree's analysis indicates that between SMEs and EMP, the Kendall rank correlation coefficient is the highest. Dißmann et al. (2013) suggested using the trees with the most span of pairwise Kendall's tau, with absolute values as weights when selecting the vines' structure. The tree-selection algorithm (the strongest dependencies of C-vine tree in terms of pairwise Kendall's tau certainty empirical values) suggests the choice of SMEs as the C-vine root. The first tree node order is decided upon as SMEs, Employee, and GDP. This order showed that the most important variable was SMEs.
The first root node models the dependence by using the bivariate copulas for every pair for one specific variable at the beginning of the first $\mathrm{C}$-vine tree. The second root node modeled the pairwise dependencies depending on this variable concerning a second variable. Firstly, the tree expanded by choosing the root node for each tree. Subsequently, all pairwise dependencies are modeled based on all previous root nodes for those particular nodes. These expanded processes show a star structure of $\mathrm{C}$-vine trees.

The sufficient pair-copula recognized from families Gaussian, Student-t, Clayton, Gumbel, and Frank was related to the structure of $\mathrm{C}$-vine, and chosen in the earlier step. This study selected Gaussian and Gumbel copulas for the earliest tree as these copulas are the most suitable for SMEs-EMP and SMEs-GDP pairs, respectively. A scoring method initiated by Vuong (1989) was employed as it has goodness-of-fit tests. The sequential method was used for estimating the corresponding copula parameters. Based on Kendall's tau, a preliminary independence test is used to determine possible independent conditional variable pairs (Genest \& Favre 2007). The parameters derived from the sequential technique are employed as the beginning value to improve the estimated result to identify the corresponding MLE estimates. For the second level, the best copula fit is Student-t copula. Table 4 shows the parameters estimation result.

TABLE 4. Estimation results of C-Vine Copula

\begin{tabular}{|c|c|c|c|c|c|}
\hline & Copula & Parameter & & Kendall's tau & Tail dependence \\
\hline SMEs-EMP & Gaussian & $\begin{array}{c}0.678 \\
(0.023)\end{array}$ & - & 0.474 & - \\
\hline SMEs-GDP & Gumbel & $\begin{array}{c}4.558 \\
(0.319)\end{array}$ & - & 0.781 & $(\mathrm{U}=0.836, \mathrm{~L}=0.000)$ \\
\hline EMP-GDP\SMES & Student- $\mathrm{t}$ & $\begin{array}{l}-0.246 \\
(0.240)\end{array}$ & $\begin{array}{c}2.000 \\
(0.984)\end{array}$ & -0.158 & $(\mathrm{U}=0.112, \mathrm{~L}=0.112)$ \\
\hline
\end{tabular}

*Note: The value in the parentheses indicates the standard error of the parameters 
Table 4 summarizes the overall result of $\mathrm{C}$-vine copula estimation. The results show that all the estimated parameters are significant at 5\% level. All the dependency of the variables was positive, and the SME-GDP pair is the strongest dependence with Kendall's tau value 0.781 . Table 4 also stated a negative dependency between EMP-
GDP with the existence of SMEs, which show a -0.158 value by Kendall's tau.

The model of D-vine copula was also fitted and reported in Table 5. A similar procedure of development of D-vines followed by selecting a particular order for the variables.

TABLE 5. Estimation results of D-Vine copula

\begin{tabular}{|c|c|c|c|c|c|}
\hline & Copula & $\begin{array}{l}\text { Parameter } \\
\text { (S.E.) }\end{array}$ & & $\begin{array}{l}\text { Kendall's } \\
\text { tau }\end{array}$ & Tail dependence \\
\hline SMEs-EMP & Gaussian & $\begin{array}{c}0.678 \\
(0.023)\end{array}$ & - & 0.474 & - \\
\hline EMP-GDP & Gaussian & $\begin{array}{c}4.558 \\
(0.319)\end{array}$ & - & 0.566 & - \\
\hline SMEs-GDP $\backslash$ EMP & Frank & $\begin{array}{l}-0.246 \\
(0.240)\end{array}$ & - & 0.599 & $(\mathrm{U}=0.680, \mathrm{~L}=0.000)$ \\
\hline
\end{tabular}

*Note: The value in the parentheses indicates the standard error of the parameters

Table 5 summarizes the overall result of the D-vine copula estimation. All the estimated parameter results are significant at the 5\% level. Kendall's tau showed that the strongest dependence is SMEs-GDP on condition that EMP has a Kendall's tau value of 0.599. Based on the Kendall's tau value, all the pairs showed positive dependence. The results also showed that for the beginner tree, the best copula for both SMEs-EMP and EMP-GDP pairs was the Gaussian copula. The Frank copula seems to fit well with the pair given at the second level. The results suggest a positive correlation and dependence between the three variables, SMEs, economic growth, which is shown by GDP, and employees.

The calculation of the Voung test, which involved the $p$-value, log-likelihood, AIC, and BIC, was implemented in this study as a comparison for the two-fitted vine copulas models. The condensed result is shown in Table 6 .

TABLE 6. The C-Vine and D-Vine copulas compared

\begin{tabular}{lcc}
\hline & C-Vine & D-vine \\
\hline Log-likelihood & 538.144 & 519.320 \\
AIC & -1068.287 & -1032.639 \\
BIC & -1057.867 & -1024.824 \\
Vuong Test & 0.000 & \\
\hline
\end{tabular}

*Note: The table shows the comparison value of log-likelihood, AIC, BIC, and p-value of the Vuong test for the C and D-vine copula models 
Measurement of the distance between two statistical models was done under the Vuong test and was compared with the two non-nested models. The $\mathrm{C}$-vine has greater log-likelihood 538.144 compared to the D-vine, as well as AIC and BIC figures. The AIC and BIC for the C-vine model, -1068.287 and -1057.867, respectively, were smaller compared to the D-vine. The test of the two vine structures shows that the more suitable model was the $\mathrm{C}$-vine copula compared to the $\mathrm{D}$-vine copula model. It can be concluded that the $\mathrm{C}$-vine copula model is a better fit for explaining the dependence of the multivariate for the variables; it can furnish more views because of the specific structures.

\section{DISCUSSION AND CONCLUSION}

The copula analysis was used in this study to investigate the nature of the linkage between the three main variables of interest. The data used in this study was yearly data from 1998-2017. These findings add to our understanding of the dependency between SMEs' growth, economic growth, and also the SMEs' total number of employees in Malaysia. By utilizing the vine copula approach, this study explored the density of the dependency between the SMEs' growth, economic growth, and the total number of employees in the SME sector in Malaysia.

Moreover, the accurate linkage between SMEs, the total number of employees, and economic growth plays a crucial role in any policy formulation. The results show there is a strong positive correlation between them. The strongest dependence is between SMEs' growth and the total number of employees, followed by dependence between SMEs and economic growth (GDP). Assuming that the growth of SMEs is linked to many other things, it is expected that the greater the growth of SMEs, the greater their productivity, and they will need more employees, leading to more favorable economic growth. In the absence of the SME sector, the increase in the total number of employees may also decline, and the development of economic growth will be diminished. Determining the accurate dependence between the three variables (SMEs, economic growth, and SMEs' employees) is critical. Given the linkage of SMEs to economic growth and the total number of employees, policymakers should design and implement policies that can improve the development of SMEs to boost economic growth.
Overall, the results indicate that there is a positive, strong dependency between SMEs' growth, economic growth, and the total number of employees. The findings of this study appear in line with most of the literature previously discussed. The evidence from this study contributes to existing knowledge on the relationship of economic growth, SMEs' growth, and the total number of employees, with copula shedding additional information on these linkages. As the backbone of Malaysia's economic growth, SMEs continue to play a vital role in its economy as the country attempts to realize its goal of achieving developed country status by the year 2020 (Bank Negara Malaysia 2008). Improving the intensity of the dependency of this variable is vital in ensuring Malaysia's future development.

When new data appears, further study will be required to investigate the connections between SME growth, SME employees' growth, and the country's economic development to determine whether the findings in this study are consistent. This research may be done in other countries, especially in developing countries, to observe the dependency between the three variables, which will assist policymakers in their efforts for quicker and healthier economic growth.

\section{ACKNOWLEDGEMENTS}

This research would not be possible without the sponsorship of the Public Service Department, Malaysia, and the grant from the Universiti Kebangsaan Malaysia GGPM-2018-070.

\section{REFERENCES}

Adeoye, A. \& Abu, Z. 2015. The effect of entrepreneurship on economy growth and development in Nigeria. International Journal of Development and Economic Sustainability 3(2): 49-65.

Aloui, R. \& Ben Aissa, M.S. 2016. Relationship between oil, stock price and exchange rate: A vine copula based GARCH method. The North American Journal of Economic and Finance 37: 458-471.

Altman, E. \& Sabato, G. 2007. Modelling credit risk for SMEs: Evidence from the US market. Abacus 43(3): 332-357.

Audretsch, D.B. \& Keilbach, M. 2004. Entrepreneurship capital and economic performance. Journal of Regional Studies 38(8): 949-959.

Ayandibu, O.A. \& Houghton, J. 2017. The role of small and medium scale enterprise in local economic development 
(LED). Journal of Business and Retail Management Research 11(2): 133-139.

Ayozie, D.O. \& Latinwo, H.K. 2010. Entrepreneurial developments and small scale industry contribution to Nigerian national development: A marketing interface. Information Management and Business Review 1(2): 51-68.

Bank Negara Malaysia. 2008. Laporan Tahunan BNM. http://www.bnm.gov.my/index.php? ch=bm publication $\& p g=b m \_a r \& a c=29 \&$ lang $=b m$. Accessed on 10 April 2019.

Barro, R. 2002. Quantity and Quality of Economic Growth. Chile: Central Bank of Chile.

Beck, T., Demirguc-Kunt, A. \& Levine, R. 2005. SMEs, growth, and poverty: Cross-country evidence. Journal of Economic Growth 10(3): 199-229.

Bedford, T. \& Cooke, R.M. 2002. Vines-a new graphical model for dependent random variables. The Annals of Statistics 30(4): 1031-1068.

Bedford, T. \& Cooke, R.M. 2001. Probability density decomposition for conditionally dependent random variables modeled by vines. Annals of Mathematics and Artificial Intelligence 32: 245-268.

Bello, A., Jibir, A. \& Ahmed, I. 2018. Impact of small and medium scale enterprises on economic growth: Evidence from Nigeria. Global Journal of Economics and Business 4(2): 236-244.

Cheng, Y., Du, J. \& Ji, H. 2020. Multivariate joint probability function of earthquake ground motion prediction equations based on vine copula approach. Mathematical Problem in Engineering 2020: 1697352.

Chinweuba, E.T. \& Sunday, C.O. 2015. Quantitative analysis of the impact of small and medium scale enterprises on the growth of Nigerian economy: (1993-2011). International Journal of Development and Emerging Economics 3(1): 26-38.

Craig, S.G., Carlos, L.R. \& Alex, F.D. 2008. SME competitive strategy and location behavior: An exploratory study of high-technology manufacturing. Journal of Small Business Management 46(2): 183-202.

Czado, C., Min, A., Baumann, T. \& Dakovic, R. 2009. Pair-copula Constructions for Modeling Exchange Rate Dependence. Technical report. Technische Universität München.

Dißmann, J., Brechmann, E.C., Czado, C. \& Kurowicka, D. 2013. Selecting and estimating regular vine copula and application to financial returns. Computational Statistics \& Data Analysis 59: 52-69.

DOSM. 2019. Press Release: Small and Medium Enterprises (SMEs) Performance 2018. Department of Statistic Malaysia (DOSM).

Genest, C. \& Favre, A.C. 2007. Everything you always wanted to know about copula modeling but were afraid to ask. Journal of Hydrologic Engineering 12(4): 347-368.
Habaradas, R.B. 2008. SME development and technology upgrading in Malaysia: Lessons for the Philippines. Journal of International Business Research 7(Supp. Special Issue 1): 89-116.

Hu, M.W. 2010. SMEs and economic growth: Entrepreneurship or employment. ICIC Express Letters 4(6A): 2275-2280.

Joe, H. 1996. Families of m-variate distributions with given margins and $\mathrm{m}(\mathrm{m}-1) / 2$ bivariate dependence parameters. In Distribution with Fixed Marginals and Related Topics, edited by Ruschendorf, L., Schweizer, B. \& Taylor, M.D. Hayward: Institute of Mathematical Statistics. pp. 120141.

Karadag, H. 2016. The role of SMEs and entrepreneurship on economic growth in emerging economies within the post-crisis era. Turkey Journal of Small Business and Entrepreneurship Development 4(1): 22-31.

Kurowicka, D. \& Cooke, R.M. 2006. Uncertainty Analysis with High Dimensional Dependence Modelling. Chichester: John Wiley \& Sons.

Leegwater, A. \& Shaw, A. 2008. The Role of Micro, Small and Medium Enterprises in Economic Growth: Across-Country Regression Analysis. Micro report 135. United States Agency for International Development.

Leonelli, S., Masciarelli, F. \& Fontana, F. 2019. The impact of personality traits and abilities on entrepreneurial orientation in SMEs. Journal of Small Business \& Enterpreneurship https://doi.org/10.1080/08276331.2019. 1666339.

Liao, R., Boonyakunakorn, P., Liu, J. \& Sriboonchitta, S. 2019. Modelling dependency structure of crude oil prices and stock market of developed and developing countries: A C-Vine copula approach. Journal of Physics: Conference Series 1324(1): 012097.

Lussier, R.N., Bandara, C. \& Marom, S. 2016. Entrepreneurship success factors: An empirical investigation in Sri Lanka. World Journal of Entrepreneurship, Management and Sustainable Development 12(2): 102-112.

Malaysia SME Corp. 2019. SME annual report 2018/19. https:// www.smecorp.gov.my/images/SMEAR/SMEAR2018_2019/ final/english/SME\%20AR \%20-\%20English\%20-\%20 All\%20Chapter\%20Final\%2024Jan2020.pdf. Accessed on 3 January 2020.

Malaysia SME Corp. 2014. SME annual report 2013/14 http://www.smecorp.gov.my/index.php/en/sme-annualreport-2013-14. Accessed on 10 April 2019.

Muritala, T.A., Awolaja, A.M. \& Bako, Y.A. 2012. Impact of small and medium enterprises on economic growth and development. American Journal of Business and Management 1(1): 18-22.

Nager, T., Swanepoel, E. \& Van Der Merwe, M.A. 2014. Introduction to entrepreneurship and small business management. Pretoria: UNISA Press 3: 316-320. 
Opafunso, Z.O. \& Adepoju, O.O. 2014. The impact of small and medium scale enterprises on economic development of Ekiti State, Nigeria. Journal of Economics and Sustainable Development 5(16): 115-122.

Prusa, J. 2010. Productivity of Czech small and medium enterprises: Lagging behind their potential. Journal of Industry Competition and Trade 10(3): 343-363.

Roopchund, R. 2020. SMEs in Mauritius: Economic growth, employment and entrepreneurial culture. International Journal of Entrepreneurship and Small Business 39(4): 585-596.

Scheers, L.V. 2016. Is there a link between economic growth and SMEs success in South Africa. Investment Management and Financial Innovations 13(2): 249-353.

Sun, H. 2019. The price linkage between oil, gold, stock and exchange rate based on vine copula. IOP Conference Series: Materials Science and Engineering. p. 012021.

TalentCorp Malaysia. 2015. Eleventh Malaysia Plan 2016-2020: Anchoring Growth on People.

https://www.talentcorp.com.my/clients/ TalentCorp_2016_7A6571AE-D9D0-4175-B35D99EC514F2D24/contentms/img/publication/RMKe-11\%20 Book.pdf. Accessed on 10 April 2019.

Tambunan, T. 2008. SME development, economic growth and government intervention in a developing country: The Indonesian story. Journal of International Entrepreneurship 4(2): 111-133.

Vermeulen, B. 2011. Press Release Issued by Sentient Communications. http://www.itweb.co.za/index. php?option $=$ com_content\&view $=$ article\&id $=45967 \#$ prcont acts. Accessed on 2 September 2019.
Vuong, Q.H. 1989. Likelihood ratio tests for model selection and non-nested hypotheses. Econometrica 57(2): 307-333.

Wang, Y. 2016. What are the biggest obstacles to growth of smes in developing countries? - an empirical evidence from an enterprise survey. Borsa Istanbul Review 16(3): 167-176.

Wozniaka, M., Dudaa, J., Gąsiorb, A. \& Bernatb, T. 2019. Relations of GDP growth and development of SMEs in Poland. Procedia Computer Science 159: 2470-2480.

Yoshino, N. \& Taghizadeh-Hesary, F. 2016. Major challenges facing small and medium sized enterprises in Asia and solutions for mitigating them. ADBI Working Paper 564. http://www.adb.org/publications/majorchallenges-facingsmall-and-medium-sized-enterprises-asia-and-solutions/.

Mazmira Adan \& Saiful Izzuan Hussain*

Department of Mathematical Sciences

Faculty of Science and Technology

Universiti Kebangsaan Malaysia

43600 UKM Bangi, Selangor Darul Ehsan

Malaysia

Mazmira Adan

Department of Statistics, Malaysia

Federal Government Administrative Center 62514 Putrajaya, Federal Territory

Malaysia

*Corresponding author; email: sih@ukm.edu.my

Received: 19 May 2020

Accepted: 11 December 2020 